\title{
Nishi Memorial Award in Gastric Cancer
}

(c) The International Gastric Cancer Association and The Japanese Gastric Cancer Association 2019

The Japanese Gastric Cancer Association (JGCA) established the "Nishi Memorial Award in Gastric Cancer" to commend high-quality papers published in Gastric Cancer. In each volume of the Journal, three articles are selected by the Editorial Committee, and the JGCA awards 100,000 Japanese yen to the first authors.

For volume 21, the following articles were selected.

A non-randomized confirmatory trial of an expanded indication for endoscopic submucosal dissection for intestinal-type gastric cancer (cT1a): the Japan Clinical Oncology Group study (JCOG0607).

Endoscopic submucosal dissection for early gastric cancer meeting the expanded criteria for intestinaltype gastric cancer (cT1a) was an effective and safe procedure, and should be considered as a standard treatment.

Gastric Cancer 2018;21:114-123.

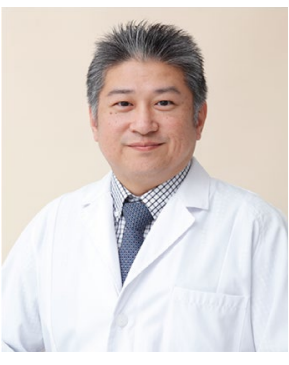

Noriaki Hasuike

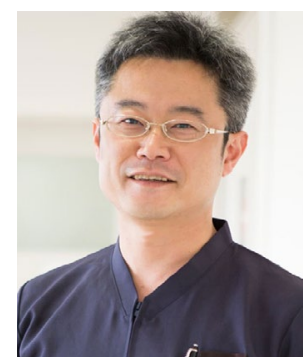

Kazutaka Obama

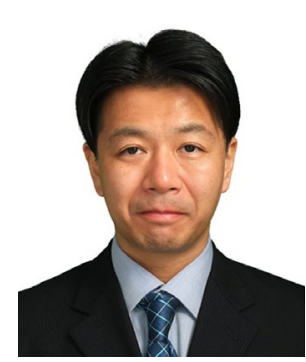

Toshiaki Hirasawa

Publisher's Note Springer Nature remains neutral with regard to jurisdictional claims in published maps and institutional affiliations. 